\title{
Worked examples of alternative methods for the synthesis of qualitative and quantitative research in systematic reviews Patricia J Lucas ${ }^{1}$, Janis Baird ${ }^{2}$, Lisa Arai ${ }^{3}$, Catherine Law $^{4}$ and Helen M Roberts*3
}

\author{
Address: ${ }^{1}$ School for Policy Studies, University of Bristol, 8 Priory Rd, Bristol BS8 1TZ, UK, ${ }^{2}$ MRC Environmental Resource Centre, University of \\ Southampton, UK, ${ }^{3}$ Child Health Research \& Policy Unit, City University, UK and ${ }^{4}$ Institute of Child Health, University College London, UK \\ Email: Patricia J Lucas - patricia.lucas@bristol.ac.uk; Janis Baird - jb@mrc.soton.ac.uk; Lisa Arai - l.arai@city.ac.uk; \\ Catherine Law - c.law@ich.ucl.ac.uk; Helen M Roberts* - h.roberts@city.ac.uk \\ * Corresponding author
}

Published: 15 January 2007

BMC Medical Research Methodology 2007, 7:4 doi:10.1 186/I47I-2288-7-4
Received: 09 October 2006 Accepted: 15 January 2007

This article is available from: http://www.biomedcentral.com/l47/-2288/7/4

(C) 2007 Lucas et al; licensee BioMed Central Ltd.

This is an Open Access article distributed under the terms of the Creative Commons Attribution License (http://creativecommons.org/licenses/by/2.0), which permits unrestricted use, distribution, and reproduction in any medium, provided the original work is properly cited.

\begin{abstract}
Background: The inclusion of qualitative studies in systematic reviews poses methodological challenges. This paper presents worked examples of two methods of data synthesis (textual narrative and thematic), used in relation to one review, with the aim of enabling researchers to consider the strength of different approaches.

Methods: A systematic review of lay perspectives of infant size and growth was conducted, locating 19 studies (including both qualitative and quantitative). The data extracted from these were synthesised using both a textual narrative and a thematic synthesis.

Results: The processes of both methods are presented, showing a stepwise progression to the final synthesis. Both methods led us to similar conclusions about lay views toward infant size and growth. Differences between methods lie in the way they dealt with study quality and heterogeneity.

Conclusion: On the basis of the work reported here, we consider textual narrative and thematic synthesis have strengths and weaknesses in relation to different research questions. Thematic synthesis holds most potential for hypothesis generation, but may obscure heterogeneity and quality appraisal. Textual narrative synthesis is better able to describe the scope of existing research and account for the strength of evidence, but is less good at identifying commonality.
\end{abstract}

\section{Background}

The inclusion of qualitative data in systematic reviews is an area of ongoing methodological development [1-3], with particular problems arising for reviews attempting to synthesise quantitative with qualitative data. The Cochrane qualitative methods group [2] suggests four areas in which development is needed; (1) searching, (2) critical appraisal, (3) synthesis/summary, and (4) loss of research context. This paper aims to contribute to development in the synthesis of qualitative and quantitative data. Alternative models and vocabularies of synthesis are emerging [3-9], but standard methods for combining different data types from the qualitative and quantitative research traditions have not yet been agreed [8]. 
Innovative methods are often developed during the course of research, but in general, papers report methods only briefly. As a result, the material that could inform learning is more often to be found in filing cabinets than in journals. In this paper we aim to distinguish between "the trivial and non-trivial points of divergence" p.31 [4] by providing worked examples of two methods of evidence synthesis (thematic and textual narrative) tested in one systematic review.

\section{Methods}

A systematic review of lay views about infant size and growth was undertaken as part of a series of interlinked reviews examining the evidence for associations between early growth and a number of later outcomes. The systematic review of views included both qualitative and quantitative studies.

Study methods and findings are reported in greater detail elsewhere [10-13]. Standard systematic review methods were employed, following guidance from the Centre for Reviews and Dissemination [14] and from an advisory group with backgrounds in public health, paediatrics, infant nutrition, qualitative and quantitative methods, systematic reviewing, and including representatives from user groups. Twelve databases were searched using terms for growth, height, weight and infancy as well as appropriate methodological terms. 2,694 abstracts were retrieved, from which 19 studies met the inclusion criteria for the review.

Two researchers independently extracted findings by interrogating each study using the following questions developed from the aims of the review:

\section{What is healthy growth/size?}

2. How important is growth/size to participants?

3. What concepts are used to define healthy growth/size?

4. How do participants assess growth/size?

5. Where does growth lie among priorities for child health?

6. What information influences views/behaviour?

\section{Who influences views/behaviour?}

Directly reported participant data (e.g. verbatim quotations or scores on attitudinal scales) and author interpretations were recorded separately, to retain the richness or 'thickness' of the contributing data. 'Thickness' in this context refers to the kinds of relatively detailed descrip- tions and contextual material which help the reader to make judgements about the trustworthiness of the data, particularly when applying it to different contexts $[15,16]$. Study characteristics and quality assessment were summarised (for examples see Table 3). There is vigorous debate on whether qualitative research can be assessed using standard quality criteria, or whether this process is contrary to the nature of qualitative enquiry [17]. While the controversy on the use of critical appraisal in systematic reviews including qualitative data lies beyond the scope of this article, with views ranging from those who believe that critical appraisal is core to qualitative synthesis [18] to those who, like Barbour [19] consider that critical appraisal of qualitative research can be reductionist, it is notable that there is general agreement that a checklist approach to critical appraisal can bring its own problems, particularly in relation to transparency in assessing interpretative work. We took the view that applying quality criteria rigidly would be likely to exclude relevant studies that had failed to comply with a particular reporting regime. Thus, all studies meeting our inclusion criteria listed were included and quality appraisal was used at the data synthesis stage contributing to strength of evidence.

Two methods were proposed for synthesis of findings, textual narrative and thematic, both of which the advisory group agreed were appropriate to our needs. The first, the textual narrative approach, involves a commentary reporting on study characteristics, context, quality, and findings, using the scope, differences and similarities among studies were used to draw conclusions across the studies, whilst the second, the thematic approach, groups data into the themes. Given the relatively small number of studies located, it was feasible to test both methods. Findings from the review are provided briefly for illustration, but the focus of this paper is on the process of synthesis and a comparison of methods used. The two reviews ran in tandem, as the thematic review needed time for response and comparison between reviewers.

\section{Results}

Worked Example I - Textual Narrative Synthesis

Factors identified by the research team from the research literature as likely to affect views on infant growth were used to define a number of sub-groups. These were:

1. Relationship between participant and infant (e.g. mothers, other family members, health professionals, unrelated others)

\section{Weight status of participant}

\section{Ethnicity of participant}

4. Age of infant 
5. Views about infants considered 'high risk' at birth i.e. those born too small or too early, or who were placed in a neonatal intensive care unit (NICU)

\section{6 . Weight/growth status of infant after birth}

\section{Mode of infant feeding (breast fed, bottle fed, weaned)}

Using agreed versions of quality appraisal and extracted data a textual narrative synthesis was undertaken by a single researcher (PL). Each study within a sub-group was described in a commentary reporting on study characteristics, context, quality, and findings. The scope, differences and similarities among studies were used to draw conclusions across the studies (the synthesis). Drawing conclusions across studies was not always possible due to study heterogeneity and lack of data. A worked example of the process is shown in Table 1.

\section{Findings - Textual Narrative Synthesis}

We noted that unrelated members of the public tended to prefer infants of mid-range body sizes, but the evidence to support this observation was thin. Families of children with poor growth were acutely aware of growth as a problem; they monitored growth and discussed it with others. They desired "normal" growth in their child, and looked for ways that they could interpret the infant's growth as normal (for example finding members of the extended family who were of similar body shape). The most common method of assessing size in all sub-groups was by comparison with others, although the use of growth charts and physical measurement were also important for those with children with poor growth including babies born too small or too early. However, growth and size in themselves were low among concerns about such 'high risk' babies. The predominance of those with 'high risk' infants may explain our conclusion that growth was low among priorities for mothers of younger infants (aged 03 and 3-6 months). Among older children (more than 12 months) with poor growth there was concern among parents. Parents wanted to see good growth in their children, but they also considered love, attention, good health and good diet as important.

We judged that we had insufficient data to draw conclusions about the views of family members other than mothers, health professionals, or to compare the views of participants of different weight, ethnicity, or toward breast versus bottle fed infants.

\section{Worked Example 2 - Thematic Synthesis}

Thematic synthesis was undertaken by two researchers, LA and PL. Findings from all studies were collated under the 7 questions used in data extraction. Each researcher independently conducted a thematic analysis using these findings. On initial discussion of themes, researchers judged that there was repetition between the data extraction questions, and that data referred to four broad areas of enquiry:

\section{Understanding healthy growth/size}

Table I: Stepwise textual narrative synthesis

\begin{abstract}
Step I: Study grouping. Studies belonging to each of the sub-groups were identified. For example studies classified by relationship between participant and infant were:

a) Mothers; 16 studies $[20,28-4 I]$

b) other family members; I study [20]

c) health professional; 2 studies $[28,42]$

d) unrelated others; 2 studies [43-45]

There was overlap between sub-groups. For example a study of mothers 2 months after their infants were admitted to NICU would fall within 3 groups, determined by the 'participants being mothers', the 'age of the infant's and the fact that the infants were considered 'high risk'.

Step 2: Study commentaries produced. These commentaries summarised key aspects of the studies in relation to the sub-group within which they were included. For example a study of mothers' views:

A study by Baughcum and colleagues[28] reported on focus groups conducted with 14 mothers attending WIC clinics (Special Supplemental Nutrition Program for Women, Infants and Children) in USA with infants aged I2-36 months. The study focussed on maternal attitudes to feeding and proposed an association between these and overweight in their babies. The study design was judged adequate, although the bias introduced by sampling from WIC clinics was not discussed by study authors. Authors concluded that mothers are more concerned about under- than overweight; two supporting quotations stated that weight gain is always good, because it means children are eating.

Step 3: Sub-group synthesis produced. For example the views of mothers:

Most of the studies in this review (16/19) explored the views of mothers. The mothers, varied in terms of the age of their infants, the present and past health status of their children, their country of residence, their country of origin, income level, socio-economic status (SES), and number of children. North American Caucasians made up most of the sample. Background data for participants was often unknown, unreported or incomplete. Sampling strategies in the studies created difficulties in interpreting findings. For example, three studies explicitly set out to sample low income groups $[28,29,37]$ using WIC clinics to achieve this. To be recruited to these studies, families needed to have a low income, but also needed to register for the WIC programme and attend clinics. This strategy is likely to selectively recruit participants [29]. Studies typically did not allow comparison between groups (for example those from different ethnic backgrounds) because findings were not reported separately.

Growth and size were concerns for mothers, particularly achieving average or normal growth. Mothers used a variety of sources of information to define norms, including growth charts, clothing and familial patterns of growth/size. There was evidence of concern for underweight, but the extent of concern about overweight was unclear.
\end{abstract}




\section{Assessment of growth/size}

\section{Concerns about growth/size}

4. Influences on views, behaviour, interpretations of growth/size

Data and themes were grouped into these areas and emerging themes were then considered for relevance, presence across studies, 'thickness' and duplication. This process was repeated until researchers were satisfied that all data could be interpreted within these themes and an agreed version reached. A worked example of the process is shown in Table 2.

\section{Findings - Thematic Synthesis}

Across the thematic synthesis the predominant concern of participants was normality. This was seen through the creation of norms of growth and models to explain difference. This was conducted across physical, observable characteristics, but included physical unobservable (such as underlying health status) and non physical (such as emotional care) dimensions. Where growth differed from the norm and a plausible explanation could not be found, for example among families of those with faltering growth [20], growth became an important concern for parents.

Data from across studies could be usefully combined in this method, for example in listing all the sources of influence on behaviour or views found. Family, other parents and friends, information from the infant themselves, health professionals, clothing sizes, magazines, books, radio, TV and their religious beliefs were all important to some, but the relative importance of these could not be explored.

\section{Strengths and limitations of our study}

While the data extraction and thematic synthesis was undertaken by two researchers working independently, only one of these researchers (employed to work on the qualitative aspect of the review) worked on the narrative synthesis with a second researcher discussing the work as it progressed. Whether the findings might be different with more than one researcher working on both syntheses, or researchers not involved in the data extraction doing the syntheses, or the syntheses being carried out in a different order, are themselves research-able (if rather expensive) questions, as is the issue of whether the immersion of one researcher in the data at every stage a strength (as we believe it to be) or a source of bias.

\section{Discussion}

Reassuringly, the conclusions to which these analyses led us about lay perspectives were largely similar across the thematic and textual narrative synthesis. Whether using a different research team, or a larger number of reviewers, would have produced different results is itself a researchable question. However, in this case conclusions from both analyses were dominated by importance of having babies that were a 'normal' size, leading to interest in monitoring of growth in a number of ways and, sometimes, to concern that there was an underlying problem leading to 'abnormal' growth. While the general conclusions were the same, the process and the implications of the two types of synthesis differed.

\section{Strengths and Weaknesses of Textual Narrative Synthesis Methods}

A textual narrative approach typically groups studies into more homogenous groups. This technique has been particularly successful in synthesising different types of research evidence (e.g. qualitative, quantitative, economic). Examples include a number of reviews carried out by the Evidence for Policy and Practice Information and Co-ordinating Centre (EPPI-Centre) [21-23], reviews of tobacco use and exposure to tobacco smoke [24], reviews of ultrasound in pregnancy [25] and of communication between health care professionals and patients about prescribing [26].

In our review, the textual synthesis proved a useful way to describe difference in the included studies, making explicit the diversity in study designs and contexts. The textual narrative review also described gaps in the literature, both by showing where evidence was absent and by making an evaluation of the strength of evidence in different areas. Using this method enabled us to comment on, for example, the ethnic uniformity of participants, and the lack of evidence collected regarding mode of feeding.

However, transparency remained a problem. For example, decisions about which sub-groups to use for synthesis of individual studies rely on judgements, albeit ones which can be informed by the scientific literature and by lay views. While we sought to make the decision making process clear, interpretation and judgement, which are not fully susceptible to external scrutiny, lie at the heart of the process.

\section{Strengths and Weaknesses of Thematic Synthesis}

The strengths of the thematic synthesis lie in its potential to draw conclusions based on common elements across otherwise heterogeneous studies. This synthesis is potentially more accessible for the reader than a textual synthesis. Conclusions from this thematic synthesis fulfil an important research aim of qualitative research in generating hypotheses, an area to which traditional systematic reviews are poorly suited [27]. 
Table 2: Stepwise thematic synthesis

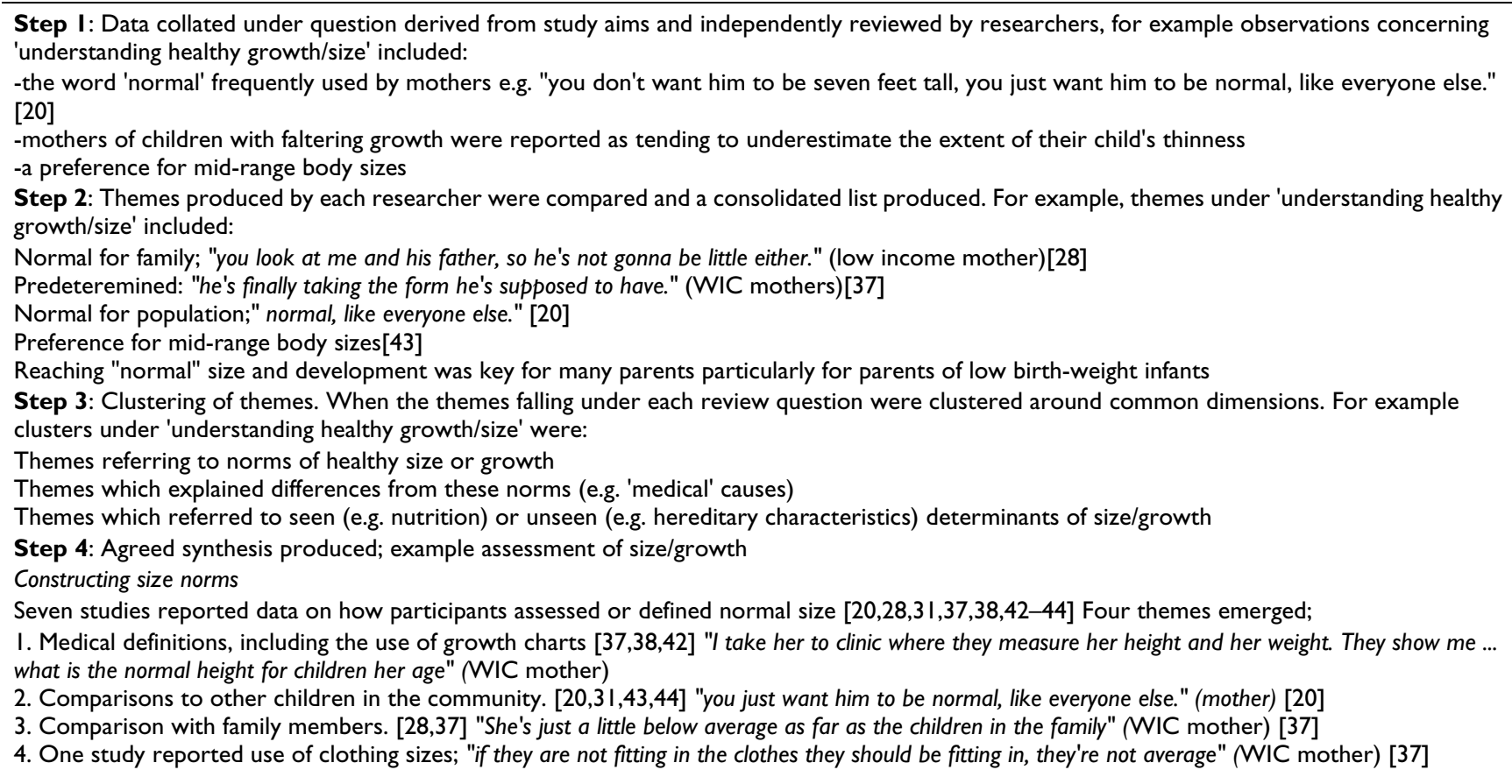

Table 3: Example study summaries

\begin{tabular}{|c|c|c|c|c|c|}
\hline Study & $\begin{array}{l}\text { Participants } \\
\text { Location } \\
\text { Design }\end{array}$ & $\begin{array}{l}\text { Aims (where possible } \\
\text { verbatim) } \\
\text { Appraisal of Methods }\end{array}$ & $\begin{array}{l}\text { Infant age } \\
\text { Participation rate } \\
\text { Attributable } \\
\text { quotations }\end{array}$ & $\begin{array}{l}\text { Setting } \\
\text { Sampling } \\
\text { Triangulation }\end{array}$ & Key findings \\
\hline Baughcum et al. 1998 & $\begin{array}{l}\text { I } 6 \text { dieticians, } 6 \text { WIC* } \\
\text { mothers, } 8 \text { teenage } \\
\text { WIC mothers } \\
\text { Kentucky, USA } \\
\text { Qualitative (focus } \\
\text { groups) }\end{array}$ & $\begin{array}{l}\text { "to identify maternal } \\
\text { beliefs and practices } \\
\text { about child feeding that } \\
\text { are associated with the } \\
\text { development of } \\
\text { childhood obesity" } \\
\text { Design allowed for } \\
\text { exploration of } \\
\text { subjective experience. }\end{array}$ & $\begin{array}{l}\text { 12-36 months age } \\
\text { Not stated for } \\
\text { mothers, } 95 \% \text { for } \\
\text { dieticians } \\
\text { Not attributable to } \\
\text { individuals }\end{array}$ & $\begin{array}{l}\text { WIC* clinic and WIC* } \\
\text { nurses } \\
\text { Risk of bias as } \\
\text { sampling restricted to } \\
\text { health clinic users } \\
\text { Not stated }\end{array}$ & $\begin{array}{l}\text { Mothers were not } \\
\text { concerned about } \\
\text { overweight in their } \\
\text { children. This was } \\
\text { perceived as a } \\
\text { problem by dieticians } \\
\text { and study authors. }\end{array}$ \\
\hline Baughcum et al. $200 \mathrm{I}$ & $\begin{array}{l}454 \text { mothers, } 258 \\
\text { attending WIC* and } \\
196 \text { attending private } \\
\text { child health clinics. } \\
\text { Cincinatti \& Kentucky, } \\
\text { USA } \\
\text { Quantitative } \\
\text { attitudinal (closed } \\
\text { questionnaire) }\end{array}$ & $\begin{array}{l}\text { "to determine if the } \\
\text { factor scores [from } \\
\text { questionnaire under } \\
\text { development] were } \\
\text { associated cross- } \\
\text { sectionally with ( } 1 \text { ) the } \\
\text { child being overweight } \\
\text { at the time of the } \\
\text { survey (2) maternal } \\
\text { obesity, and (3) lower } \\
\text { socio-economic } \\
\text { status." } \\
\text { Design did not allow } \\
\text { for subjective views. }\end{array}$ & $\begin{array}{l}\text { II-24 months, but } \\
\text { considering } \\
\text { retrospectively to first } \\
\text { year. } \\
98 \% \\
\text { Not attributable to } \\
\text { individuals }\end{array}$ & $\begin{array}{l}\text { Health clinics (WIC* } \\
\text { or private) } \\
\text { Risk of bias as } \\
\text { sampling restricted to } \\
\text { health clinic users } \\
\text { Not stated }\end{array}$ & $\begin{array}{l}\text { Mothers were more } \\
\text { concerned about } \\
\text { under eating and } \\
\text { underweight, although } \\
\text { where children were } \\
\text { overweight there was } \\
\text { concern about } \\
\text { overeating and } \\
\text { overweight. }\end{array}$ \\
\hline
\end{tabular}

\footnotetext{
* Special Supplemental Nutrition Program for Women, Infants and Children
} 
However, pooling findings in the thematic synthesis risks masking the shortcomings of the individual studies that make up the review. Although descriptions of study characteristics and quality appraisal were presented alongside synthesised findings, the synthesis process obscured these in the conclusions. We believe that further debate about the reliability of this approach would be useful. On the one hand, the hypotheses that emerge from this synthesis draw on a broader body of views than any single study (as in a meta-analysis) and may therefore increase reliability; on the other, we risk making strong conclusions based on a group of studies none of which is in itself reliable on the grounds of quality or diversity of context. This method may also be poor at examining contradictions, as well as commonalities, in the data and at highlighting gaps in the evidence.

\section{Conclusion}

The selection of synthesis method for systematic reviews such as this may depend on the aims of the synthesis. For the purpose of generating future research hypotheses, the thematic synthesis appears to hold the greatest potential; describing common themes and providing a possible structure for new research. In contrast, the textual narrative synthesis might be better suited to reviews which aim to describe the existing body of literature; identifying the scope of what has been studied, the strength of evidence available, and gaps that need to be filled.

\section{Competing interests}

The authors declare no competing interests.

\section{Authors' contributions}

$\mathrm{CL}, \mathrm{JB}, \mathrm{HR}$, obtained funding for the study. All authors were responsible for the concept and design of the study. $\mathrm{PL}$, and HR carried out the review work with assistance from all other authors. PL, LA \& HR were responsible for the interpretation of findings. PL and HR produced the first and subsequent drafts of the paper, all authors were responsible for critical revision of the manuscript.

\section{Acknowledgements}

We would like to thank our advisory group for their input to the project, especially Paul Dieppe for chairing it, Sandy Oliver and David Jones for methodological advice and Phyll Buchanan for the additional lay input. Jos Kleijnen assisted $C L$, JB and HR in obtaining funding for the study and provided methodological advice. This project was funded by the Department of Health in the UK, and we thank them for their support. The views expressed in this report are those of the authors and not necessarily those of the Department of Health.

\section{References}

I. Petticrew M, Roberts H: Systematic Reviews in the Social Sciences. A Practical Guide. Oxford, UK, Blackwell Publishing; 2006.

2. CQMG: Cochrane Qualitative Methods Group. 2007 [http:// www.joannabriggs.edu.au/cqrmg/index.html].
3. Popay J, Roberts H, Sowden A, Pettticrew M, Arai L, Rodgers M, Britten N: Guidance on the conduct of narrative synthesis in systematic reviews. http://www lancs ac uk/fass/projects/nssr/ 2007.

4. Dixon-Woods M, Agarwal S, Young B, Jones DR, Sutton AJ: Integrative approaches to qualitative and quantitative evidence. London, Health Development Agency; 2004.

5. Harden A: Extending the boundaries of systematic reviews to integrate different types of study: examples of methods developed within reviews of young people's health. In Moving beyond effectiveness in evidence synthesis Edited by: Popay J. London, National Institute for Health \& Clinical Excellence; 2006:15-30.

6. Campbell R, Britten N, Pound P, Donovan J, Morgan M, Pill R, Pope C: Using meta-ethnography to synthesise qualitative research. In Moving beyond effectiveness in evidence synthesis Edited by: Popay J. London, National Institute for Health \& Clinical Excellence; 2006:75-82.

7. Dixon-Woods M, Bonas S, Booth A, R JD, Miller T, Sutton AJ, Shaw RL, Smith J A, Young B: How can systematic reviews incorporate qualitative research? A critical perspective. Qualitative Research 2005, 6:27-44.

8. CQMG: Methodological Issues Arising from the Inclusion of Qualitative Evidence in Systematic Reviews. http://www lancs ac uk/fass/ihr/research/public/cochrane htm 2007.

9. Shaw RL, Booth A, Sutton AJ, Miller T, Smith J A, Young B, Jones DR, Dixon-Woods M: Finding qualitative research: an evaluation of search strategies. BMC Medical Research Methodology 2004, 4:.

10. Baird J, Fisher D, Lucas P, Kleijnen J, Roberts H, Law C: Being Big or Growing Fast; a systematic review of size and growth in infancy and later obesity. British Medical Journal 2005, 331:929-934.

II. Baird J, Lucas P, Kleijnen J, Fisher D, Roberts H, Law C: Defining optimal infant growth for lifetime health: a systematic review of lay and scientific literature. 2005 [http:// www.mrc.soton.ac.uk/index.asp?.page=176].

12. Fisher D, Baird J, Payne L, Lucas P, Kleijnen J, Roberts H, Law C: Are infant size and growth related to burden of disease in adulthood? A systematic review of literature. International Journal of Epidemiology 2006, 35: I 196-1210.

13. Lucas P, Arai L, Baird J, Kleijnen J, Law C, Roberts H: A systematic review of lay views about infant size and growth. Archives of Disease in Childhood 2007.

14. NHS Centre for Reviews and Dissemination: Undertaking systematic reviews of research on effectiveness: CRD's guidance for those carrying out or commissioning reviews. Volume 4 (2nd Edition). CRD; 2001.

15. Arai L, Popay J, Roen K, Roberts H: It might work in Oklahoma but will it work in Oakhampton? What does the effectiveness literature on domestic smoke detectors tell us about context and implementation? Injury Prevention 2005, I I:I48-I5I.

16. Popay J, Rogers A, Williams G: Rationale and standards for the systematic review of qualitative literature in health services research. Qualitative Health Research 1998, 8:34I-35I.

17. Dixon-Woods M, Bonas S, Booth A, R JD, Miller T, Sutton AJ, Shaw $R L$, Smith J A, Young B: How can systematic reviews incorporate qualitative research? A critical perspective. Qualitative Research 2006, 6:27-44.

18. Attree $P$, Milton B: Critically appraising qualitative research for systematic reviews: defusing the methodological cluster bombs. Evidence \& Policy 2006, 2:109-126.

19. Barbour RS: Checklists for improving rigour in qualitative research: a case of the tail wagging the dog? British Medical Journal 200I, 322: III - III7.

20. Thomlinson $E H$ : The lived experience of families of children who are failing to thrive. Journal of Advanced Nursing 2002, 39:537-545.

21. Shepherd J, Garcia J, Oliver S, Harden A, Rees R, Brunton G, Oakley $A$ : Barriers to, and facilitators of the health of young people: A systematic review of evidence on young people's views and on intervention in mental health, physical activity and health eating. Volume 2: Complete Report. 2002 [http:// eppi.ioe.ac.uk]. London, EPPI-Centre, Social Science Research Unit, Institute of Education

22. Harden A, Garcia J, Oliver S, Rees R, Shepherd J, Brunton G, Oakley $A$ : Applying systematic review methods to studies of people's views: an example from public health research. In Volume 58. J Epidemiol Community Health; 2004:794-800. 
23. Oliver S, Harden A, Rees R, Shepherd J, Brunton G, Garcia J, Oakley $A$ : An emerging framework for including different types of evidence in systematic reviews for public policy. In Volume II. Evaluation; 2005:446.

24. Hopkins DP, Briss PA, Ricard CJ, Husten CG, Carande-Kulis VG, Fielding JE, McKenna JW, Sharp DJ, Harris JR, Wollery TA, Harris $\mathrm{KW}$ : Reviews of evidence regarding interventions to reduce tobacco use and exposure to environmental tobacco smoke. American Journal of Preventive Medicine 200I, 20:I6-66.

25. Garcia J, Bricker L, Henderson J, Martin M, Mugford M, Nielson J, Roberts T: Women's views of pregnancy ultrasound: A systematic review. Birth 2002, 29:225-250.

26. Cox K, Stevenson F, Britten N, Dundar Y: A Systematic review of communication between patients and health care professionals about medicine-taking and prescribing. King's College London, GKT Concordance Unit, Guys' King's and St Thomas' School of Medicine; 2003.

27. Dixon-Woods M, Cavers D, Agarwal S, Annandale E, Arthur A, Harvey J, Katbamna S, Olsen R, Smith L, Riley R, Sutton AJ: Conducting a critical interpretative synthesis of the literature on access to healthcare by vulnerable groups. BMC Medical Research Methodology 2006, 6:

28. Baughcum AE, Burklow KA, Deeks CM, Powers SW, Whitaker RC: Maternal feeding practices and childhood obesity: a focus group study of low-income mothers. Archives of Pediatrics \& Adolescent Medicine 1998, I52:1010-1014.

29. Baughcum AE, Powers SW, Johnson SB, Chamberlin LA, Deeks CM, Jain A, Whitaker RC: Maternal feeding practices and beliefs and their relationships to overweight in early childhood. In Volume 22. J Dev Behav Pediatr; 2001:391-408.

30. Hewat RJ, Ellis DJ: Similarities and differences between women who breastfeed for short and long duration. In Volume 2. Midwifery; 1986:37-43.

31. May KM: Searching for normalcy: mothers' caregiving for low birth weight infants. In Volume 23. Pediatr Nurs; 1997: 17-20.

32. McCann JB, Stein A, Fairburn CG, Dunger DB: Eating habits and attitudes of mothers of children with non-organic failure to thrive. Archives of Disease in Childhood 1994:234-236.

33. Pridham KF: Information needs and problem solving behavior of parents of infants. Birth Defects: Original Article Series 1984, 20: $125-165$.

34. Sturm LA, Drotar D, Laing K, Zimet GD: Mothers' beliefs about the causes of infant growth deficiency: is there attributional bias? Journal of Pediatric Psychology 1997, 22:329-344.

35. Hall WA, Shearer K, Mogan J, Berkowitz J: Weighing preterm infants before $\&$ after breastfeeding: does it increase maternal confidence and competence? In Volume 27. MCN Am J Matern Child Nurs; 2002:318-326.

36. Rajan L, Oakley A: Low birth weight babies: the mother's point of view. In Volume 6. Midwifery; 1990:73-85.

37. Reifsnider E, Allan J, Percy M: Mothers' explanatory models of lack of child growth. Public Health Nursing 2000, I 7:434-442.

38. Sherratt F, Johnson A, Holmes S: Responding to parental concerns at the six-month stage. Health Visitor 1991, 64:84-86.

39. Smith MP: Postnatal concerns of mothers: an update. Midwifery 1989, 5: 182-188.

40. Kramer MS, Barr RG, Leduc DG, Boisjoly C, Pless IB: Maternal psychological determinants of infant obesity. Development and testing of two new instruments. Journal of Chronic Diseases 1983, 36:329-335.

41. Brown MM: An exploration of parental concerns about preterms and full term infants during the first nine months of life. University of California, Los Angeles, USA; I981:I-I 22.

42. Vehvilainen-Julkunen $\mathrm{K}$ : The function of home visits in maternal and child welfare as evaluated by service providers and users. Journal of Advanced Nursing 1994, 20:672-678.

43. Rand CSW, Wright BA: Continuity and change in the evaluation of ideal and acceptable body sizes across a wide age span. International Journal of Eating Disorders 2000, 28:90-100.

44. Rand CSW, Wright BA: Thinner females and heavier males: Who says? A comparison of female to male ideal body sizes across a wide age span. International Journal of Eating Disorders 200I, 29:45-50.

45. Birgenaeu CT: Body Image in Infancy. Adult body weightrelated biases applied to infants. Univeristy of Massachesetts Boston, USA; 200I:I-127.

\section{Pre-publication history}

The pre-publication history for this paper can be accessed here:

http://www.biomedcentral.com/1471-2288/7/4/prepub
Publish with Biomed Central and every scientist can read your work free of charge

"BioMed Central will be the most significant development for disseminating the results of biomedical research in our lifetime. "

Sir Paul Nurse, Cancer Research UK

Your research papers will be:

- available free of charge to the entire biomedical community

- peer reviewed and published immediately upon acceptance

- cited in PubMed and archived on PubMed Central

- yours - you keep the copyright

Submit your manuscript here:

http://www.biomedcentral.com/info/publishing_adv.asp
BioMedcentral 